\title{
Mediação da Informação em Turismo: um estudo introdutório
}

\author{
Mediation of Information in Tourism: an introductory study
}

\begin{abstract}
Juliana Medaglia
Doutoranda em Ciência da Informação pela Escola de Ciência da Informação da Universidade Federal de Minas

Gerais - UFMG.

Professora Adjunta do Curso de Turismo da Universidade dos Vales do Jequitinhonha e Mucuri - UFVJM. E-mail: julianamedaglia@ hotmail.com
\end{abstract}

Cristina Dotta Ortega

Doutora em Ciência da Informação pela Escola de Comunicações e Artes da Universidade de São Paulo - USP. Professora Adjunta da Escola de Ciência da Informação da Universidade Federal de Minas Gerais - UFMG.

E-mail: ortega@eci.ufmg.br

\begin{abstract}
Resumo
O turismo é uma atividade presente na sociedade contemporânea e que vem, de um lado, sendo popularizado como atividade de lazer acessível a uma parcela considerável da população mundial, e, de outro, gerando interesse acadêmico como objeto de estudo. Nesses contextos, o turismo possui vínculo marcante com a informação, da qual depende e com a qual interage constantemente. Apresenta-se aqui uma reflexão acerca da relação entre essas áreas, considerando a utilização das metodologias da Ciência da Informação para a atividade turística, a partir dos desafios e possibilidades da mediação no contexto informacional turístico. Para tanto, metodologicamente, lançou-se mão de pesquisa bibliográfica, analisando fontes secundárias acerca dos temas. Os principais resultados das relações propostas apontam para semelhanças entre as áreas de Ciência da Informação e Turismo, especialmente no que diz respeito ao caráter aplicado dos estudos dessas áreas. Além disso, ante a dependência que o turismo possui em relação à informação, seja por parte dos turistas que a usam para tomar a decisão de viajar, seja por parte dos atores do turismo que a usam para potencializar seus serviços, mas também quanto ao estudo do fenômeno, observa-se a importância da mediação da informação como um elemento chave da comunicação turística e do processo de construção do conhecimento turístico.
\end{abstract}

Palavras-chave: Informação em Turismo. Mediação da Informação.

\begin{abstract}
Tourism is a marked contemporary activity, growing, in the one hand, in terms of popularity as leisure option for a considerable share of the population around the world, and, in the other hand, generating academic interest as an object of study. In either situation, tourism has a remarkable bond with information, on which depends and interacts. Considering this relation, a reflection about these areas is presented in this study, bearing in mind the use of Information Science for Tourism activity, highlighting the challenges and possibilities for mediation in tourism informational context. Hence, a bibliographic research was carried out, looking through secondary sources on the themes. The main results for the suggested relation point out to similarities between Information Science and Tourism areas, especially in terms of the applied characteristics of their studies. Moreover, it is possible to notice the dependence on information tourism presents, either for a tourist use in choosing a destination, or for an academic research, with a great amount of information available in each case. Due to this fact, the importance of mediation is sustained in terms of building tourism knowledge, as a key element for communication.
\end{abstract}

Keywords: Tourism Information. Mediation of Information.

InCID: R. Ci. Inf. e Doc., Ribeirão Preto, v. 6, n. 2, p. 126-147, set. 2015/fev. 2016. 


\section{Introdução}

Considerando a atividade turística, é possível elucubrar que a partir da informação dáse o seu incremento, com base em duas questões. A primeira é que, sem informação, é impossível planejar o desenvolvimento turístico de um destino, e a segunda é que a partir da informação se dão a motivação, a decisão e a realização de viajar. Deste modo, este estudo apresenta como proposta refletir acerca da informação em turismo, considerando a utilização das metodologias da Ciência da Informação para a atividade turística. A intenção é tratar do processo de mediação da informação em turismo, portanto, observando a aplicação da Ciência da Informação ao Turismo.

Ambas as áreas podem ser pensadas como ciências sociais aplicadas, no sentido de que seus estudos buscam subsidiar modos de intervir nas diversas atividades humanas, sensibilizando comunidades para o aproveitamento de certos conteúdos ou de atividades (turísticas), além de discutir as motivações e os resultados destas ações. Outra característica comum à Ciência da Informação e ao Turismo diz respeito ao modo como se desenvolveram, com forte presença do senso comum na condução de seus processos e em sua construção científica, residindo nessa temática parte expressiva do encontro entre teoria e prática, ou pensar e agir, no âmbito das ciências sociais aplicadas. Entendemos que se trata "de objeto teórico que se constitui pela articulação de objetos empíricos, como pessoas, processos, instrumentos e produtos, cuja orientação é essencialmente pragmática" (ORTEGA, 2012, p. 12). No entanto, estes encontros, muitas vezes, são marcados mais pela opinião do que pelo rigor. Neste contexto, é que é preciso apontar a importância de compreender a informação em turismo como forma de não se deixar escapar suas possibilidades, inclusive para o desenvolvimento científico do turismo.

Além da contextualização a partir das ciências sociais aplicadas, a opção por colocar como condição problematizadora a mediação ecoa em outros autores, como tratado à frente, que destacam a necessidade de se pensar o conceito de mediação de forma a subsidiar um debate voltado à epistemologia da mediação. Silva (2010, p. 9) menciona que "o conceito de mediação prima pela ausência, o que permite inferir que até hoje não foi sujeito a um exercício de apropriação e ajustamento pelos especialistas em Ciência da Informação". Esta afirmação conduz nossa curiosidade científica nessa direção. 
Desde os grandes feitos considerados históricos até a mais simples e cotidiana ação do homem, a informação se faz presente. De transações internacionais a pequenas tarefas familiares, todas dependem da informação para acontecer. Se tal constatação não é novidade, a discussão contemporânea se dá em torno do desafio de promover o reconhecimento, por grupos sociais diversos, de informações pertinentes e potencializadoras das atividades que desenvolvem ou podem vir a desenvolver, diante de tantas informações produzidas e disseminadas na sociedade atual.

Ações de mediação da informação fornecem possibilidades diversas de ação cotidiana, profissional, familiar, religiosa, de lazer. Nesse contexto, Smit (2012) destaca que, contribuir para a melhoria das condições de vida do homem e da sociedade, por meio do acesso à informação, é o principal objetivo da Ciência da Informação. Assim, justifica-se refletir acerca dos desafios e possibilidades da mediação no contexto informacional turístico. Contribuir para a escolha e a postura crítica dos seus usuários em relação à informação passa pelos processos de mediação em jogo, quer seja para o planejamento estratégico de um destino realizado pelos membros da cadeia produtiva do turismo, quer seja para a 'viagem dos sonhos' dos turistas.

Daí a importância de se desenvolver o objetivo proposto nesse artigo, de tratar o lugar da informação em turismo, explorando o conceito de mediação nesse encontro, no qual são inúmeras as possibilidades de oferecer à sociedade respostas, caminhos e produtos. Para isso, metodologicamente, emprega-se a análise de fontes secundárias com a realização de pesquisas bibliográficas. Assim, na primeira parte deste trabalho, procuramos estabelecer uma contextualização entre Ciência da Informação e Turismo para, em seguida, apresentarmos diretamente ponderações acerca da informação em turismo como objeto. Nos dois tópicos seguintes, discutimos Mediação da Informação e, por fim, no último tópico, são apresentadas algumas considerações finais acerca do estudo. 


\section{Turismo e Ciência da Informação}

A sociedade globalizada e os processos produtivos passam, atualmente, por transformações significativas que recriam modelos sociais desde a reorganização de núcleos familiares a transformações profundas no mercado de trabalho gerando, entre outras consequências, cenários extremamente competitivos. A relação desse processo com as ciências sociais é indicada por Minayo (1994, p. 21) ao destacar o fato de seu objeto ser histórico, ou seja:

Significa que as sociedades humanas existem num determinado espaço, num determinado tempo, que os grupos sociais que as constituem são mutáveis e que tudo, instituições, leis, visões de mundo são provisórios, passageiros, estão em constante dinamismo e potencialmente tudo está para ser transformado.

Nesse contexto, é possível apontar que a relação entre globalização e aumento da concorrência foi bem exemplificada pela Organização Mundial do Turismo (2004, p. 25) ao afirmar que, "em 1959, os 15 primeiros destinos do mundo contabilizavam 87\% das chegadas internacionais, em 1970 este número era de 75\%, e já em 2000 somente 62\%”, demonstrando a dispersão da demanda turística entre os destinos que surgiram. Por conseguinte, o estudo do fenômeno turístico vem acompanhando as transformações da sociedade contemporânea e, a partir das diversas áreas que interagem na atividade turística, vem desenvolvendo, investigando, pesquisando e criando seus próprios estudos e teorias, em um processo claro de amadurecimento, profissionalização e, até mesmo, popularização do acesso ao turismo e ao lazer.

Paralelamente ao desenvolvimento do turismo como fenômeno social (e econômico) está o desenvolvimento da ciência no contexto da pós-modernidade, em que paradigmas são colocados na berlinda. Esse processo se deu a partir das realidades que cercam as pesquisas. Assim, de acordo com Bourdieu, Chamboredon e Passeron (1999, p. 24)

Pelo fato de que, no momento da observação ou experimentação, o sociólogo estabelece uma relação com o objeto que, enquanto relação social, nunca é puro conhecimento, os dados apresentam-se-lhe como configurações vivas, singulares e, em poucas palavras, humanas demais, que tendem a se impor como estruturas do objeto.

Além da discussão entre o comprometimento e a sinergia do objeto e suas relações sociais, Bulmer ${ }^{1}$ (1978 apud MINAYO, 1994) questiona a classificação tradicional que divide a pesquisa em 'pura' e 'aplicada', considerando que pesquisas teóricas apresentam

\footnotetext{
${ }^{1}$ BULMER, M. Social policy research. Londres: The Macmillan, 1978.
} 
consequências para a realidade, ao mesmo tempo em que as pesquisas aplicadas necessitam de um arcabouço teórico para sua realização.

Analisando o turismo como fenômeno social e acompanhando as transformações na ciência na contemporaneidade, pode-se colocar que é nesse contexto que o mesmo se veste de ciência e que a informação se organiza cientificamente. As possibilidades se multiplicam aproximando ciências e linhas de atuação que separadamente percorriam caminhos de desenvolvimento lado a lado, mas que chegam, então, a se encontrar. De acordo com Shera (1980² apud SMIT, 2009, p. 63), “a Ciência da Informação foi constituída como uma ciência aplicada, recorrendo a teorias desenvolvidas por outras áreas do conhecimento e, de acordo com alguns autores, fundada na prática profissional". Por sua vez, o turismo começou a ser visto como um fenômeno a ser estudado no século passado, sendo incorporado como objeto de pesquisa por diversas áreas mais consolidadas.

Como menciona Santos (2010, p. 21), a ciência clássica, como paradigma dominante, impunha uma visão racionalista do mundo que supunha um modelo científico que rompia com o senso comum como "um modelo totalitário, na medida em que nega o caráter racional a todas as formas de conhecimento que não se pautarem pelos seus princípios epistemológicos e pelas suas regras metodológicas". Nesse contexto, Araújo (2003, p. 24) lembra que:

\begin{abstract}
A Ciência da Informação aproxima-se exatamente do modelo positivista e funcionalista. Como já vinha de uma formalização muito próxima à das ciências exatas, a ciência da informação encontrou, exatamente naquele conjunto de ciências sociais também próximas às ciências exatas, maior identidade de propostas e métodos.
\end{abstract}

A amplitude de áreas como o Turismo e a Ciência da Informação demoraria a gerar interesse científico não fosse o contexto da pós-modernidade, no qual se desenvolvem discussões de interdisciplinaridade. Olga Pombo $(1994,2005)$ aponta que as discussões a respeito acontecem no âmbito escolar e após revisar conceitos de interdisciplinaridade de diversos autores aponta que

a palavra interdisciplinaridade é objecto de significativas flutuações: da simples cooperação de disciplinas ao seu intercâmbio mútuo e integração recíproca ou, ainda, a uma integração capaz de romper a estrutura de cada disciplina e alcançar uma axiomática comum. (POMBO, 1994, p. 10)

A proximidade entre Turismo e Ciência da Informação se intensifica pela característica do processo de integração disciplinar, muitas vezes em torno de um mesmo

\footnotetext{
${ }^{2}$ SHERA, J. H. Sobre biblioteconomia, documentação e ciência da informação. In: GOMES, H. E. (Org.). Ciência da informação ou informática? Rio de Janeiro: Calunga, 1980. p.91-105.
} 
objeto. De acordo com Pombo (1994, p. 12) neste processo "a pluridisciplinaridade seria o pólo mínimo de integração disciplinar, a transdisciplinaridade o pólo máximo e a interdisciplinaridade o conjunto das múltiplas variações possíveis entre os dois extremos". Essa compreensão do conhecimento interdisciplinar é corroborada pelas pesquisadoras da área da Ciência da Informação, Tálamo e Smit, para quem o conhecimento interdisciplinar "não é meramente descritivo, não se apresenta como operacionalização que visa à uniformização e generalização [...] se constrói como atividade tradutora, fundada em diversas linguagens, sobre um determinado tema” (TÁLAMO; SMIT, 2007, p. 51).

Pode-se dizer que o mesmo ocorre com toda a pesquisa do fenômeno turístico, por seu caráter multi e interdisciplinar, como atesta Pearce (2003), para quem o turismo atraiu o interesse dos pesquisadores de várias disciplinas, entre as quais se encontram o marketing, a economia, a geografia, a administração de empresas, a sociologia, a antropologia e as ciências políticas, entre outras. É possível encontrar pesquisas e projetos que apresentam a atividade turística como objeto em todas estas áreas.

Em um contexto tão vasto diante do mesmo objeto, observa-se a necessidade das escolhas teóricas e epistemológicas em torno desse objeto, como forma de garantir o desenvolvimento científico e, quiçá, durante o processo científico, conseguir alcançar a transdisciplinaridade discutida por Pombo como etapa de fusão entre as disciplinas, depois que a multidisciplinaridade (ou pluri) e a interdisciplinaridade, com todas suas nuances e desafios, já se fizeram presentes (POMBO, 1994, 2005).

Outra proximidade entre as áreas de Turismo e Ciência da Informação está relacionada ao (menor) rigor científico quando da busca por interlocução com outras áreas. Smit, Tálamo e Kobashi ${ }^{3}$ (2004 apud SMIT 2009, p. 64) expõem que existe uma alta proporção de 'noções emprestadas' de outras ciências e incorporadas ao discurso da Ciência da Informação e que isto a converte em uma "interdisciplinaridade formal, que não reflete a interdisciplinaridade real, mas um 'empréstimo' de termos de outras áreas, sem que tenha havido uma adaptação dos conceitos aos propósitos da área”. Essa constatação parece configurar, a partir dos estudos de Pombo (1994, 2005), mais multidisciplinaridade, ou seja, juntar lado a lado muitas disciplinas, do que o encontro promovido pela interdisciplinaridade para se chegar à transdisciplinaridade.

\footnotetext{
${ }^{3}$ SMIT, J. W., TÁLAMO, M. F. G. M., KOBASHI, N. Y. A determinação do campo científico da Ciência da Informação: uma abordagem terminológica. DataGramaZero, Rio de Janeiro, v. 5, n. 1, fev. 2004.
} 
Esse panorama é encontrado também no turismo que, para além de não possuir ainda um corpo próprio de conhecimentos, vivencia os empréstimos de outras áreas, muitas vezes abordadas de forma dicotômica, ou seja, centradas no ponto de vista econômico (a atividade turística gera deslocamento de recursos financeiros em todo o mundo) ou a partir do panorama social (as consequências desses deslocamentos de recursos financeiros e de pessoas geram impactos nas comunidades nas quais o turismo acontece). Assim demonstra Barretto (2003, p. 21) ao afirmar que sendo o negócio apenas uma parte do fenômeno turístico, analisá-lo somente a partir dos paradigmas econômicos levam ao esquecimento da dimensão antropológica, pois os turistas não são vistos como pessoas, mas como simples portadores de dinheiro. Contudo, "ao mesmo tempo, tratar o turismo somente a partir da dimensão socioantropológica e ambiental leva ao esquecimento das suas derivações no plano econômico, o que pode constituir-se numa visão romântica deslocada das atuais condições históricas" (p. 21).

Logo, é possível afirmar que ambas as áreas, Ciência da Informação e Turismo, parecem buscar um corpo de conhecimento que possa ser reconhecido como próprio e que as identifique, o que envolve o contexto social no qual estão inseridas.

Informação e tomada decisão não podem ser dissociados da dinâmica sistêmica da atividade turística. De forma mais objetiva, é possível exemplificar com o mercado de viagens que lida com incalculáveis bancos de dados, ou ainda, com as informações na área pública de diversas fontes usadas para fins turísticos, ou, até mesmo com a produção de informações de destinos que compõem guias de viagens, entre outros. Por isso, a importância em refletir e problematizar a informação em turismo, como segue. 


\section{Informação em Turismo}

O turismo já foi definido por autores oriundos das mais diversas áreas do saber que estudam o fenômeno turístico. A definição mais usual tem sido a da Organização Mundial do Turismo (2001, p. 38), segundo a qual "o turismo compreende as atividades realizadas pelas pessoas durante suas viagens e estadas em lugares diferentes do seu entorno habitual por um período consecutivo inferior a um ano, por lazer, negócios ou outros". Outra definição abrangente, e quiçá mais técnica, é apresentada por Andrade (1995, p. 38), para quem o "turismo é o conjunto de serviços que tem por objetivo o planejamento, a promoção e a execução de viagens, e os serviços de recepção, hospedagem e atendimento aos indivíduos e aos grupos, fora de suas residências habituais". Sob essa ótica, considera-se a atividade turística centrada no deslocamento intencional de pessoas e os processos envolvidos neste deslocamento.

A relação mútua entre o que as pessoas desejam de um destino e o que este pode oferecer caracteriza os conceitos de oferta e demanda aplicados ao turismo que irão condicionar o desenvolvimento turístico de uma localidade. Do ponto de vista da informação, oferta e demanda trabalham em medidas diferentes, porém com a mesma essencialidade. Afinal, de nada adianta ofertar um destino bem estruturado, com atrativos diferenciados, acesso razoável e serviços de qualidade, se não houver turistas para demandá-lo. O contrário também é verdadeiro. Se turistas prontos para o consumo da experiência turística não encontrarem um destino minimamente estruturado (com atrativos diferenciados, acesso, gente acolhedora, locais para se hospedar e se alimentar), irão deixá-lo sem retornar ou indicar a outros. Assim, para a gestão de destinos turísticos existe a necessidade de informações estruturadas para o seu planejamento, desde o inventário de seus atrativos até as condições econômicas da região na qual está inserido; as informações são essenciais para saber qual turista buscar ou que área de negócios incentivar naquele destino. Já para o turista, a pesquisa de informações é essencial para a decisão e realização de uma viagem, seja junto a uma agência de viagens ou informalmente, em consultas a amigos, sites ou redes sociais.

Além disso, com o desenvolvimento de estudos na área do turismo, identificou-se que a atividade se adequa com muita pertinência aos conceitos sistêmicos e, nesse viés, Panosso Netto (2005) chega a afirmar que a visão sistêmica é paradigmática no estudo do turismo. De fato a interdependência dos elementos na área de turismo é facilmente perceptível e os 
modelos propostos internacionalmente desde os anos 1970 com Leiper ${ }^{4}$ (apud LOHMANN; PANOSSO NETTO, 2008), até os anos 1990 no Brasil, com Beni (2001), demonstram invariavelmente a relação intrínseca entre oferta e demanda no turismo.

O turismo tem na informação insumo central de seu processo de desenvolvimento, devido à necessidade de deslocamento do turista até o destino escolhido previamente, onde realizará suas atividades de lazer e onde se dará o consumo do conjunto de serviços que constituem o produto turístico. Comparado com outros serviços, o turismo apresenta algumas singularidades, mas comunga de características intrínsecas a qualquer serviço, quais sejam: a) intangibilidade (não resulta em propriedade), b) perecibilidade (não pode ser estocado), c) inseparabilidade (produção e consumo simultâneos) e d) heterogeneidade (não é possível produzir serviços idênticos). Esse contexto cria uma necessidade de tangibilização dos produtos para os turistas e dos processos de planejamento e prestação de serviços para os profissionais da área, fazendo da informação matéria prima para o desenvolvimento da própria atividade turística. Cacho e Azevedo (2010, p. 45) comentam a amplitude do papel da informação em turismo:

A informação é o principal instrumento e ferramenta de trabalho de um profissional da área. Sem informação não existe turismo, pois o ator principal desse processo, o turista, não reside no local a ser visitado.

Assim, intencionando trazer esse processo de contextualização da informação para o turismo, buscou-se um livro recente, mas que vem sendo considerado um marco na literatura científica de Turismo no Brasil por compilar as principais teorias da área. Trata-se do livro Teoria do Turismo: conceitos, modelos e sistemas, dos pesquisadores Guilherme Lohmann e Alexandre Panosso Netto, já em sua segunda edição, mas cuja primeira data de 2008. Por meio de seu índice remissivo, recuperou-se a palavra 'Informação', que consta nos seguintes capítulos:

\footnotetext{
${ }^{4}$ LEIPER, N. The framework of tourism: towards a definition of tourism, turist, and the tourist industry. Annals of Tourism Research, v. 6, p. 390-407, 1979.
}

InCID: R. Ci. Inf. e Doc., Ribeirão Preto, v. 6, n. 2, p. 126-147, set. 2015/fev. 2016. 
Quadro 1: A informação na obra Teoria do Turismo

\begin{tabular}{ll}
\hline \multicolumn{1}{c}{ Capítulo } & \multicolumn{1}{c}{ Enfoque } \\
\hline $\begin{array}{l}\text { Sistema Turístico de Cuervo (pioneiro } \\
\text { da teoria de sistemas em turismo) }\end{array}$ & A informação como parte do sistema turístico. \\
Lazer & $\begin{array}{l}\text { Informação como parte do conjunto de ocupações que compõem os } \\
\text { momentos de Lazer dos indivíduos. }\end{array}$ \\
Pós-modernidade e Turismo & $\begin{array}{l}\text { Informação aliada à tecnologia como forma de educar } \\
\text { consumidores (turistas) e prestadores de serviços (atores do } \\
\text { turismo) }\end{array}$ \\
Mercado Turístico & $\begin{array}{l}\text { Informação como componente das ferramentas de promoção } \\
\text { calcadas na tecnologia (websites, portais de viagens on-line) que } \\
\text { permitiram a abertura dos mercados, considerando compradores } \\
\text { /turistas de qualquer parte do mundo. }\end{array}$ \\
Informação enquanto ferramenta de tomada de decisão estratégica \\
para a formação de regiões turísticas por suas similaridades e não a \\
partir de questões políticas e/ou geográficas.
\end{tabular}

Fonte: elaboração própria a partir de Lohmann e Panosso Netto (2008).

Dos sete elementos do Quadro 1, três pertencem à área de mercado e comercialização (mercado, modelo conceitual de Klenosky \& Gitelson e canais de distribuição), colocando a informação como central nesse processo e indo ao encontro da necessidade de tangibilização por meio da informação, já citada nesse tópico. Outras duas citações versam a respeito de processos mais estratégicos (sistema turístico de Cuervo e cluster de turismo), nos quais a informação é colocada como essencial para a tomada de decisão. Por fim, é possível citar o estudo científico do turismo, apoiado nas ciências sociais, com apenas duas citações (pósmodernidade e lazer).

De Lucca Filho (2005, p. 32) organizou uma compilação da relação turismo e informação a partir de autores de referência no campo: 
Quadro 2: Relação da atividade turística com a informação

\begin{tabular}{|c|c|}
\hline Autor & Relação do turismo com a informação \\
\hline $\begin{array}{l}\text { Poon } \\
1988\end{array}$ & $\begin{array}{l}\text { Na rotina da atividade turística existe a geração, coleta, processamento, aplicação e } \\
\text { comunicação de informação. A informação é o laço que amarra todos os } \\
\text { componentes da indústria turística. Os links entre os integrantes do trade turístico } \\
\text { são os fluxos de informação. }\end{array}$ \\
\hline $\begin{array}{c}\text { Sheldon } \\
\text { 1984; } 1993\end{array}$ & $\begin{array}{l}\text { O mundo tem apresentado mudanças incontestáveis, numa velocidade cada vez } \\
\text { maior. A atividade turística - assim como uma infinidade de outras áreas - depende } \\
\text { cada vez mais da informação. A informação tem (...) uma grande importância no } \\
\text { turismo. }\end{array}$ \\
\hline $\begin{array}{c}\text { Naisbitt } \\
1994\end{array}$ & $\begin{array}{l}\text { "Com o crescimento do turismo e com a sofisticação crescente dos viajantes, a } \\
\text { demanda por informações levará a uma interconectividade [dos agentes envolvidos } \\
\text { no setor] ainda maior". (p.132) }\end{array}$ \\
\hline $\begin{array}{l}\text { Perdue } \\
1995\end{array}$ & $\begin{array}{l}\text { A disponibilidade de informações pode definir a ida de turistas para determinadas } \\
\text { localidades. Da informação depende a satisfação do turista pelo local e } \\
\text { eventualmente pode definir o retorno do turista àquela região. }\end{array}$ \\
\hline $\begin{array}{l}\text { Buhalis } \\
1998\end{array}$ & Informação é vital para a indústria de viagens \\
\hline $\begin{array}{l}\text { Trigo } \\
1999\end{array}$ & $\begin{array}{l}\text { A informação no mundo atual é produzida em massa, como uma mercadoria } \\
\text { qualquer. Pode ser vendida, consumida ou trocada. (p. } 47 \text { ) }\end{array}$ \\
\hline $\begin{array}{l}\text { O'Connor } \\
2001\end{array}$ & $\begin{array}{l}\text { A atividade turística depende cada vez mais da informação. A informação é o } \\
\text { nutriente básico do turismo. }\end{array}$ \\
\hline $\begin{array}{l}\text { Middleton } \\
2002\end{array}$ & O turismo é um mercado totalmente baseado no fornecimento de informações \\
\hline $\begin{array}{l}\text { Schertler apud } \\
\text { Stamboulis e } \\
\text { Skayannis } 2003\end{array}$ & $\begin{array}{l}\text { O turismo é o negócio da informação. A informação é o principal suporte para os } \\
\text { negócios acontecerem. }\end{array}$ \\
\hline
\end{tabular}

Fonte: De Lucca Filho (2005, p. 32)

De modo interessante, encontra-se novamente no Quadro 2 a informação na atividade turística mais relacionada à 'indústria das viagens', do que sua observação como conhecimento de um fenômeno social, antropológico e econômico. Essa constatação é perceptível também na classificação de obras nas livrarias que, quando tratam de 'turismo' costumam habitar as prateleiras dos guias turísticos e livros de viagens, enquanto que, temas acadêmicos voltados ao estudo do fenômeno são encontrados junto a publicações de 'negócios', 'economia', 'geografia', 'psicologia', entre outros.

Considerando as distintas fontes e abordagens da informação em turismo, Cacho e Azevedo (2010) afirmam que os diferentes canais de acesso à informação vêm fazendo do turista (cujas ações configuram a demanda) um cliente mais exigente e as empresas do mercado turístico (as quais se constituem na oferta) mais qualificadas.

\footnotetext{
${ }^{5}$ A terminologia trade turístico é utilizada para se referir aos entes públicos e privados que atuam direta e/ou indiretamente na atividade turística de um determinado destino, tais como: hotéis, restaurantes, agências de receptivo, centros de convenções, secretaria de turismo (atuação direta), empresas de transporte, lojas do comércio, farmácias, supermercados, associações comerciais (atuação indireta).
} 
Entretanto, a existência de informação por si só não garante que seu uso seja adequado. Isto é, ainda que haja informação em abundância, há certa resistência em confiar nas fontes, e nesse sentido, a credibilidade de quem as fornece tem um papel fundamental tanto no mercado quanto na academia. Somando a isso o fato da informação em turismo ser majoritariamente abordada a partir do mercado, como constatado nos quadros apresentados neste tópico, refletir acerca da mediação e seu papel junto aos usuários apresenta-se como caminho para o estudo da informação em turismo, conforme apresentado a seguir.

\section{Contextualização da Mediação da Informação}

Diante da dificuldade de balizar, demarcar e conceituar informação, pesquisadores da Ciência da Informação passaram a apresentar um indicativo claro de delimitação para esse conceito: a informação objeto de pesquisa na área é, prioritariamente, institucionalizada, de forma a conferir a essa informação uma espécie de 'selo de qualidade' (SMIT, 2012). Esse fato, na mediação da informação, já estabelece alguns parâmetros, pois se há uma instituição posta, o processo de mediação - e os elementos que a compõem - serão estabelecidos a partir dessa instituição.

Da mesma forma é possível colocar a questão do ponto de vista do usuário, ou seja, observando os indivíduos que buscam tais instituições é razoável estabelecer quem são habitualmente esses indivíduos, os quais serão alvo do processo de mediação. Em outro artigo, Smit insiste no contexto institucionalizado, destacando que "a seleção das informações que integrarão o sistema de informação não é, portanto, neutra, mas direcionada por objetivos institucionais" (SMIT, 2009, p. 61). Considerando a relação entre informação e instituição no âmbito da Ciência da Informação, temos que:

O objeto da Ciência da Informação relaciona-se, portanto, à intervenção que é
realizada entre a produção e o uso da informação, por meio da elaboração de
registros ou inscrições, e demais atividades que possibilitam a permanência destes
registros para acesso e usos posteriores. Está em questão um fazer informativo que
visa o uso qualificado da informação, cuja orientação é construída segundo
interesses institucionais e seus públicos, mas não subordinada acriticamente a eles
(ORTEGA, 2013, p. 3).

A questão de não subordinação abriga importante reflexão, na qual é possível destacar um primeiro encontro prático, mas que requer um olhar teórico para o papel das instituições, durante o processo de mediação, desde a produção e/ou seleção da informação, junto aos possíveis usuários. O uso da palavra 'intervenção’ acima citado aponta para um processo de 
mediação mais lógico que mecânico, mais crítico que automático, o que requer uma compreensão da totalidade da situação institucional. Ou seja, requer uma concepção clara da sua relação com a informação em questão e, por fim, um entendimento mínimo acerca do sujeito que fará uso dessa instituição e suas informações.

Contudo, é preciso destacar também a compreensão da mediação da informação sob o ponto de vista teórico em Ciência da Informação, dada a sua relevância na construção do conhecimento. A reflexão a esse respeito é de Davallon (2007, p. 19-20) para quem

Enquanto investigador, se eu quiser utilizar o termo mediação enquanto conceito, éme necessário, primeiro e antes de mais, (i) assumir que esse questionamento pertence à filosofia; (ii) mas procurar a pertinência e a validade da noção de mediação na investigação em Ciências da Informação e da Comunicação.

Silva (2010, p. 14), por sua vez, conceitua mediação de forma objetiva, estabelecendo que a mediação pode ser "entendida como instância articuladora entre diferentes partes sempre em determinadas situações e contextos", indo ao encontro da discussão inicial, estabelecida nesse tópico relacionada à informação institucionalizada. Já Almeida Júnior (2009, p. 92) apresenta um conceito mais centrado no profissional, ao colocar que mediação é

toda ação de interferência - realizada pelo profissional da informação -, direta ou indireta; [...]; singular ou plural; individual ou coletiva; que propicia a apropriação de informação que satisfaça, plena ou parcialmente, uma necessidade informacional.

A partir desse contexto e considerando o indivíduo usuário como membro da sociedade, cabe indicar o lugar da mediação neste processo como meio para se atingir a construção de conhecimento.

Oliveira (2011, p. 11) destaca também a dimensão processual da mediação ao constatar que não se trata simplesmente da relação entre sujeitos e conteúdos, mas uma "experiência que emerge e se insere no interior de dispositivos, ou seja, que atua segundo premissas, paradigmas, intenções".

Cabe destacar também a relação entre comunicação e informação que, no campo da Ciência da Informação, é muitas vezes aceita como direta, de forma a se colocar que informação implica comunicação. Entendemos que "a mediação tem como alvo a comunicação - que se dá via informação - entre a representação do objeto e o sujeito que a interpreta" (ORTEGA, 2013, p. 3). Há que se considerar que o processo de mediação colabora na construção do conhecimento, em parte por seu impacto, que implica alguma transformação da situação e não tanto, como parece ser, uma simples interação entre dois elementos ou só 
transferência de informação entre polos (DAVALLON, 2007). Contudo, o simples fato de a informação estar estruturada e apresentada em forma de documento não garante a efetividade do processo de comunicação.

Nos estudos de mediação, em especial na sua relação com a comunicação, a criação de significados é etapa do processo e caminho para a apropriação (ALMEIDA, 2012). Nesse contexto, o desafio está em encaminhar soluções para a questão da relação do usuário com a informação e, para tanto, Amorim (2007) apresenta a abordagem de Polistchuk e Trinta ${ }^{6}$, que explicitam a complexidade desse processo, colocando que:

Mediar significa criar entre duas partes um ponto de referência comum, mas
equidistante, que a uma e a outra faculte o estabelecimento de algum tipo de inter-
relação. Mediações são estratégias de Comunicação. Pelas mediações de que
participa, o ser humano representa a si próprio e aquilo que se passa em seu entorno,
fazendo com que ocorra uma positiva produção de sentidos, a serem propostos e
transacionados, e, finalmente, partilhados (POLISTCHUK e TRINTA apud
AMORIM, 2007, p. 21).

Neste pensar a mediação como estratégia de comunicação é possível considerar a representação da informação como elemento que atua na aproximação entre informação e usuário, ou seja, que cumpre papel fundamental na criação de significado para aquilo que será comunicado. Assim, tem-se a linguagem como elemento essencial à representação e recuperação da informação no contexto do processo de mediação.

A língua e os símbolos fundam as mediações, porque asseguram, no decurso do uso que é feito pelos sujeitos, a apropriação específica dos códigos colectivos, uma vez que são códigos socialmente determinados, tem regras e estruturas colectivas, que cada pessoa usa para se exprimir a título individual (RIBEIRO, 2009, p. 29).

Rejowsky e Kobashi (2011) destacam que a construção de instrumentos de mediação é coletiva, representa determinada área do conhecimento e atua entre o usuário e o sistema de informação. Cada área do conhecimento apresenta características próprias que influenciarão diretamente tais processos. Essas possibilidades de organização da informação permitem a adequação à realidade do usuário, indo ao encontro da ideia de processo de mediação que considera que a apropriação da informação só se dá na percepção do outro.

\footnotetext{
${ }^{6}$ POLISTCHUK, I.; TRINTA, A. R. Teorias da comunicação: o pensamento e a política da comunicação social. Rio de Janeiro: Campus, 2003.
}

InCID: R. Ci. Inf. e Doc., Ribeirão Preto, v. 6, n. 2, p. 126-147, set. 2015/fev. 2016. 


\section{Problematização da Mediação da Informação}

A partir da reflexão acerca do processo de mediação da informação acredita-se ter alguns alicerces para se concentrar em ponderações, problematizações e questionamentos nela implícitos. A princípio retoma-se a ponderação questionadora, por meio de Silva e Gomes (2013, p. 39), que afirmam que o conceito de mediação:

Deve ser observado de forma investigativa, factual e crítica no seio das relações cotidianas, visando conceber problematizações e reflexões científicas, o que permitiria conceber um conceito mais sólido e percepcionado de mediação.

Porém, diante das referências consultadas para a realização desta pesquisa, foi observado que a reflexão acerca do conceito de mediação não acontece com a necessária frequência e aprofundamento. O termo mediação é usado para aglutinar, sob uma mesma etiqueta, uma operação ou um conjunto de operações, menos que para significá-las. A citação de Almeida Júnior (2009, p. 91) também representa essa percepção ao colocar que "como em muitos casos os textos sobre o tema - ou que, de alguma maneira, o abordam - consideram seu conceito intuitivamente assimilado, apreendido e compreendido”. Nesse sentido, outros autores tencionam destacar a mediação como processual, por meio da relação direta entre a informação e o profissional responsável pela mediação, enfatizando a questão do significado. Conforme Sanches e Rio (2010, p. 108)

Percebemos nos estudos referentes à Mediação da Informação o conceito de
informação como uma estrutura que tem em seu cerne a potencialidade da
significância que eclode ao confrontar-se com a realidade conceitual do indivíduo e
que para isso necessita de um documento como veículo de comunicação. Nesse
sentido, o que se compreende por informação se constitui mediante um processo de
interação entre elementos disponíveis na unidade de informação, que por ora
podemos chamar de proto-informação ${ }^{7}$, e o usuário.

Dessa forma, reafirma-se a mediação como processual considerando que esta apresenta uma dimensão voltada ao contato com o usuário final, que para acontecer, exige anteriormente uma dimensão intermediária, relacionada à instituição, conforme afirmam Almeida Júnior e Bortolin ${ }^{8}$ (2008 apud TONELLO et al, 2012, p. 26):

\footnotetext{
7 Almeida Júnior (2008) adota o nome 'proto-informação' para indicar a informação registrada em documentos, estruturada com códigos da escrita, ou seja, uma possível informação ou uma 'informação latente', que para se tornar informação necessita de um processo que vai da comunicação, via documento, até a transformação do conhecimento de uma pessoa.
}

${ }^{8}$ ALMEIDA JÚNIOR, O. F.; BORTOLIN, S. Mediação da informação e da leitura. In: SILVA, T. E. (Org.). Interdisciplinaridade e transversalidade em Ciência da Informação. Recife: Néctar, 2008, p.67-85.

InCID: R. Ci. Inf. e Doc., Ribeirão Preto, v. 6, n. 2, p. 126-147, set. 2015/fev. 2016. 
A mediação, ou o fazer do profissional da informação, deve ser separada em dois momentos: a mediação explícita, que seriam as atividades-fins nos sistemas informacionais, como, por exemplo, no chamado serviço de informação e referência; e a mediação implícita, que seriam as atividades-meio, como a aquisição, o processamento da informação e outros.

Há que se considerar, portanto, que o processo de mediação, ainda que tenha seu foco na relação com o usuário, não se limita a este contato direto. Assim, acerca do papel do profissional responsável pela mediação, este pode agir consciente de sua função de intermediar, aproximando dados e indivíduos considerados independentes (PERROTTI; PIERUCCINI, 2007), bem como pode agir mecanicamente, apenas repassando informações. Do ponto de vista técnico, cabe a este profissional criar instrumentos que potencializem o acesso à informação, oferecendo ao usuário ganho de tempo e/ou de amplitude no campo da informação desejada. Refletindo acerca da informação em turismo, o profissional de turismo, quer seja no âmbito público quer na iniciativa privada, deve ponderar a centralidade da informação e seu fluxo no êxito dos negócios turísticos, considerando a informação como um elemento estratégico (BISSOLI, 1999).

Entretanto, ter a clara noção da centralidade da informação e da importância de seu fluxo acarreta também ao profissional que exerce a mediação o cuidado de realizar seu trabalho consciente do desafio de atuar sem manipular. Silva e Gomes (2013) afirmam que a mediação deve colocar o usuário como sujeito que precisa ser atraído nesse processo, e não objeto manipulado de forma arbitrária. Esta discussão é encontrada também em texto de Almeida Júnior (2007), no qual afirma que a linha entre interferência e manipulação é muito tênue e, quiçá, não perceptível. Em outro trabalho, o mesmo autor indica que a própria “informação está imersa em ideologias e em nenhuma hipótese se apresenta desnuda de interesses, sejam econômicos, políticos, culturais, etc.” (ALMEIDA JÚNIOR, 2009, p. 93). Isso quer dizer que a gênese da informação e seu uso são intencionais, e portanto, imbuídos de interesses. Nesse sentido, em uma postura mais próxima ao cotidiano e, ao mesmo tempo, calcada no processo científico, Lara e Cioffi (1998) advertem para a impossibilidade de haver neutralidade na ação dos indivíduos, justificando que a ideia de neutralidade vem como 'herança' das pesquisas ligadas às ciências da natureza, indo ao encontro do que foi discutido na primeira parte deste artigo. As autoras apontam que

é fundamental que o documentalista também se atenha a esses determinantes sociais mais globais, quando se trata de assumir uma postura técnica de análise documentária, e principalmente tenha em mente o direcionamento que vai dar para o conjunto de documentos que se propõe a tratar. Direcionamento este, que parte da linha teórica que vai imprimir a esta tarefa, desde a escolha do vocabulário que vai utilizar (Thesaurus), até o processamento técnico (seleção e indexação) e a 
recuperação da informação, que constitui a ponte para o usuário, e que permitirá finalmente o fechamento deste processo (LARA; CIOFFI, 1998, p. 94).

Do ponto de vista da informação em turismo, é possível reconhecer, como foi dito, o papel central do agente de turismo na compra de viagens e, consequentemente, na mediação de informações junto aos turistas. Ainda que as fontes de informação tenham sido ampliadas com a internet e os guias turísticos sigam sendo publicados, as agências de viagens continuam sendo procuradas pelos turistas, especialmente naquelas consideradas mais complexas, como as viagens de negócios, as internacionais, as viagens para destinos exóticos ou até mesmo aquelas que envolvem mais de um destino.

Observar o papel do profissional responsável pela mediação, neste exemplo o agente de viagens, permite retomar a problematização também a partir do contexto institucional no qual a mediação acontece, bem como a significação atribuída às informações. As decisões deste profissional precisam considerar o usuário final, retomando a ideia de que o pensar como fazer recai sobre uma ciência social aplicada, ou seja, que precisa dar respostas às questões apresentadas pela sociedade e seus membros. Ortega (2012, p. 10) afirma que:

a mediação da informação não ocorre apenas no final, ou seja, no momento em que o usuário aciona o sistema ou quando se dá o serviço de referência, mas quanto ao conjunto de propostas de significação que constituem o sistema e que são realizadas a partir dele, e demais atividades sistêmicas e contextualizadas visando apropriação da informação pelo usuário.

Nesse sentido, há um elemento intrínseco apresentado: os usuários, que constituem parte do processo de mediação, pois sem usuários não haveria 'entre quem' realizá-la. $\mathrm{Na}$ busca da compreensão do usuário, tem-se que "o usuário de informação assim se constitui quando um indivíduo é abordado a partir de um certo contexto institucional em situação de uso (real ou potencial) de informação, na perspectiva de ações profissionais, portanto, ações sistemáticas e objetivas" (ORTEGA, 2012, p. 5). Diante da colocação do indivíduo que, no contexto institucional, se torna usuário, é possível também refletir acerca do papel deste na mediação, pois alguns autores colocam que o usuário não é simplesmente um consumidor de informação, mas parte do processo de mediação, no qual acontece a produção de conhecimento a partir da informação mediada (ALMEIDA JÚNIOR, 2007; OLIVEIRA, 2011). Nessa mesma linha, Silva e Gomes (2013, p. 40) colocam que mediação é "fornecer ao usuário inúmeras possibilidades de interpretação".

O fato é que, ainda que ambos, emissor e receptor da informação, forneçam um significado a uma determinada mensagem, este processo precisa ser uma via de mão dupla. 
Nesse contexto, entre informação e usuário, a mediação aparece como um elemento da comunicação, que permite a troca social, "enquanto que os universos da produção e da recepção são a priori disjuntos por natureza" (DAVALLON, 2007, p. 22).

Dessa forma, a vontade de encontrar uma informação faz com que o usuário busque uma maneira de acessá-la. Smit (2009) destaca que o acesso à informação é um procedimento físico espacial, enquanto que sua transferência significa uma operação cognitiva, pessoal e subjetiva, de apropriação conceituação distinta da apresentada a partir de Davallon (2007), no tópico anterior. Em outras palavras, este processo de mediação, em que primeiro acesso e depois transferência se encontram, requerem ações distintas:

A discussão do acesso levantará, num primeiro momento, questões de tecnologia,
linguagem e procedimentos de organização da informação, ao passo que a
compreensão do processo de transferência pressupõe primordialmente a mobilização
de conceitos sociológicos e psicológicos. (SMIT, 2009, p. 59)

Considerando as duas esferas aqui apresentadas acerca da informação em turismo oferta e demanda - a reflexão a respeito do usuário toma proporções bastante relevantes e exige diferentes posturas do profissional de turismo enquanto mediador. A partir da oferta, considerar os membros da comunidade do destino turístico como usuários significa olhar tanto para entes públicos quanto privados, que conhecem bem as informações de seus setores (alimentação, hospedagem, receptivo, transporte, comércio, etc.), mas precisam ser contextualizados na atividade turística. Do ponto de vista da demanda, a necessidade de informação inclui aquelas que são específicas do turismo de determinado destino, mas vai muito além disso, pois condições climáticas, formas de pagamento, costumes culturais, por exemplo, são essenciais para o êxito de uma viagem, mesmos sendo características de qualquer lugar, independente de sua vocação para o turismo.

Sendo assim, é possível considerar que, dependendo da conjuntura socioeconômica, do perfil do usuário, do contexto informacional e da atuação do mediador, o processo de mediação levará a diferentes caminhos a informação em turismo. 


\section{Considerações finais}

A busca por reflexões que auxiliem a lidar com a informação em turismo mostra que, antes, há necessidade de compreender e questionar a própria Ciência da Informação, realizada nesse trabalho por meio do estudo da mediação. Procurar este entendimento e seus aspectos teóricos deixa claro que tal tarefa, comparável aos desafios científicos enfrentados no turismo, caracteriza as ciências sociais aplicadas, que se constitui, em abordagem pragmática, de áreas que se consolidam nas atividades práticas junto à sociedade. Ao mesmo tempo, Ciência da Informação e Turismo apresentam empréstimos de outras áreas do conhecimento, ponderações acerca de rigor científico e até mesmo estudos interdisciplinares mais citados que efetivamente realizados.

Da mesma forma, constata-se que a amplitude e a diversidade de compreensões e possibilidades que se enfrentam acerca do conceito de informação em Ciência da Informação, encontram lugar nas múltiplas abordagens, usos e usuários que esta mesma informação apresenta em turismo. Isso ocorre especialmente quanto à constatação de que o estudo da informação em turismo se faz mais presente nos estudos mercadológicos do que no desenvolvimento dos destinos.

Nesse contexto, refletir, questionar, problematizar a Mediação da Informação foi desafiador e esclarecedor ao mesmo tempo, por se questionar o fato da mediação não ser atividade mecânica, mas repleta de particularidades, de maneira que em todo o trabalho aqui apresentado uma afirmação, sucinta e objetiva, de Silva e Gomes (2013, p. 40), traduz coerentemente o que se propôs: "a mediação da informação pode ser afirmada em uma palavra com grande intensidade de sentido: construção" (destaque nosso). Essa afirmação encontra eco na reflexão de Lara (2007, p. 157) para quem a informação não existe de modo apriorístico, mas como "possibilidade interpretativa" que pode receber determinado significado por parte do usuário de acordo com o processo de mediação da informação que for realizado, entre outros fatores.

Assim, acredita-se que este trabalho é um primeiro passo na construção da discussão acerca da informação em turismo, que precisa ser organizada para o adequado uso de seus diversos usuários, na construção de políticas públicas e tomada de decisões privadas, para além de subsidiar a decisão de viagem dos turistas, bem como o modo como se dará a organização e o desfrute desta viagem.

InCID: R. Ci. Inf. e Doc., Ribeirão Preto, v. 6, n. 2, p. 126-147, set. 2015/fev. 2016. 


\section{Referências}

ALMEIDA JÚNIOR, O. F. Mediação da informação e múltiplas linguagens. Tendências da Pesquisa Brasileira em Ciência da Informação, Brasília, v. 2, n. 1, p. 89-103, jan./dez. 2009. Disponível em: 〈http://inseer.ibict.br/ancib/index.php/tpbci/article/view/17/39>. Acesso em: 26 mar. 2015.

. Mediação da informação e múltiplas linguagens. In: ENCONTRO NACIONAL DE PESQUISA EM CIÊNCIA DA INFORMAÇÃO, 9., 2008, São Paulo. Anais... São Paulo: Universidade de São Paulo, 2008. p. 89-103.

. Leitura, mediação e apropriação da informação. In: SANTOS, J. P. (Org.). A leitura como prática pedagógica na formação do profissional da informação. Rio de Janeiro: Biblioteca Nacional, 2007, v. 1, p. 33-45.

ALMEIDA, C. C. Mediação como processo semiótico: em busca de bases conceituais. In: ENCONTRO NACIONAL DE PESQUISA EM CIÊNCIA DA INFORMAÇÃO, 13., 2012, Rio de Janeiro. Anais... Rio de Janeiro: Fiocruz, 2012.

AMORIM, A. D. G. A mediação da informação contábil sob a ótica da ciência da informação. 2007. 202 f. Tese (Doutorado em Ciência da Informação) - Escola de Comunicações e Artes, Universidade de São Paulo, 2007.

ANDRADE, J. V. Turismo: fundamentais e dimensões. São Paulo: Ática, 1995.

ARAÚJO, C. A. A. A ciência da informação como ciência social. Ciência da Informação, Brasília, v. 32, n. 3, set./dez. 2003, p. 21-27. Disponível em:

<http://revista.ibict.br/cienciadainformacao/index.php/ciinf/article/view/29>. Acesso: 26 mar. 2015.

BARRETTO, M. O imprescindível aporte das ciências sociais para o planejamento e a compreensão do turismo. Horizontes Antropológicos, Porto Alegre, ano 9, n. 20, out. 2003, p. 15-29. Disponível em: 〈http://www.scielo.br/pdf/ha/v9n20/v9n20a01.pdf〉. Acesso: 26 mar. 2015.

BENI, M. C. Análise estrutural do turismo. 5. ed. São Paulo: Senac, 2001.

BISSOLI, M. A. M. A. Planejamento turístico municipal com suporte em sistemas de informação. São Paulo: Futura, 1999.

BOURDIEU, P.; CHAMBOREDON, J.; PASSERON, J. A profissão de sociólogo: preliminares epistemológicas. Petrópolis: Vozes, 1999.

CACHO, A. N. B.; AZEVEDO, F. F. O turismo no contexto da sociedade informacional. Revista Brasileira de Pesquisa em Turismo. v. 4, n. 2, p. 31-48, ago. 2010. Disponível em: <http://www.anptur.org.br/ojs/index.php/rbtur/article/download/266/343>. Acesso: 12 maio 2014.

DAVALlON, J. A mediação: a comunicação em processo? Prisma.com, n. 4, 2007. Disponível em: <http://revistas.ua.pt/index.php/prismacom/article/viewFile/645/pdf>. Acesso em: 26 mar. 2015. 
DE LUCCA FILHO, V. Estudo do fluxo de informações em centros de informações turísticas de Santa Catarina: Programa Portais do Lazer. Florianópolis, 2005. 134f.

Dissertação (Mestrado em Ciência da Informação) - Universidade Federal de Santa Catarina, Florianópolis, 2005.

LARA, M. L. G. A construção da informação no universo da linguagem na contemporaneidade. In: LARA, M. L. G.; FUJINO, A.; NORONHA, D. P. (Org.).

Informação e contemporaneidade: perspectivas. Recife: Néctar, 2007. Disponível em: link http://www3.eca.usp.br/sites/default/files/form/ata/pos/ppgci/publicacoes\%20\%20informacaoContemporaniedade\%281\%29.pdf acesso em: 10 set. 2015.

; CIOFFI, S. Retomando um velho tema: o mito da neutralidade da análise documentária. São Paulo em Perspectiva, v. 3, n. 1/2, p. 92-95, jan./jun. 1998.

LOHMANN, G.; PANOSSO NETTO, A. Teoria do turismo: conceitos, modelos e sistemas. São Paulo: Aleph, 2008.

MINAYO, M. C. S. O desafio do conhecimento: pesquisa qualitativa em saúde. São Paulo: Hucitec, 2004.

OLIVEIRA, A. L. A mediação da informação como experiência de negociação de sentidos. Tendências da Pesquisa Brasileira em Ciência da Informação, Brasília, v. 4, n. 1, 2011. Disponível em: <http://inseer.ibict.br/ancib/index.php/tpbci/article/viewArticle/45>. Acesso em: 26 mar. 2015.

ORGANIZAÇÃO MUNDIAL DO TURISMO. Observations on international tourism communications: report from the first world conference on tourism communications. OMT, Madrid, 2004.

Introdução ao turismo. São Paulo: Roca, 2001.

ORTEGA, C. D. A ordenação de documentos como atividade de organização da informação: proposta de fundamentação e atualização. In: ENCONTRO NACIONAL DE PESQUISA EM CIÊNCIA DA INFORMAÇÃO, 14., 2013, Florianópolis. Anais... Florianópolis: UFSC, 2013.

Ciência da informação: do objetivo ao objeto. In: ENCONTRO NACIONAL DE PESQUISA EM CIÊNCIA DA INFORMAÇÃO, 13., 2012, Rio de Janeiro. Anais... Rio de Janeiro: Fiocruz, 2012.

PANOSSO NETTO, A. Filosofia do turismo. São Paulo: Aleph, 2005.

PEARCE, D. Orientaciones actuales y futuras en la investigación turística In: ORTEGA, E. Investigación y estrategias turísticas. Madrid: Thomson, 2003.

PERROTTI, E.; PIERUCCINI, I. Infoeducação: saberes e fazeres da contemporaneidade. In: LARA, M. L. G.; FUJINO, A.; NORONHA, D. P. (Org.). Informação e contemporaneidade: perspectivas. Recife: Néctar, 2007. Disponível em: link <http://www3.eca.usp.br/sites/default/files/form/ata/pos/ppgci/publicacoes\%20\%20informacaoContemporaniedade\%281\%29.pdf>. Acesso em: 10 set. 2015. 
POMBO, O. Interdisciplinaridade e integração dos saberes. Liinc em Revista, Rio de Janeiro, v. 1, n. 1, p. 3-15, mar. 2005. Disponível em:

<http://revista.ibict.br/liinc/index.php/liinc/article/view/186/103>. Acesso em: 26 mar. 2015.

A interdisciplinaridade: conceito, problemas e perspectivas. In: POMBO, O.; LEVY, T.; GUIMARÃES, H. A interdisciplinaridade: reflexão e experiência. 2. ed. Lisboa: Texto, 1994. Disponível em: 〈www.educ.gc.ul.pt>. Acesso em: 04 nov. 2014.

REJOWSKI, M.; KOBASHI, N. Y. Subsídios para elaboração de um tesauro brasileiro de turismo. In: Turismo em análise, São Paulo, v. 22, n. 3, p. 579-598, dez. 2011. Disponível em: 〈http://www.revistas.usp.br/rta/article/view/14264〉. Acesso em: 26 mar. 2015.

RIBEIRO, F. O papel mediador da ciência da informação na construção da sociedade em rede, In: ENCONTRO NACIONAL DE PESQUISA EM CIÊNCIA DA INFORMAÇÃO, 10.,2009, João Pessoa. Anais... Florianópolis: UFPB, 2009.

SANCHES, G. A. R.; RIO, S. F. Mediação da informação no fazer do bibliotecário e seu processo em bibliotecas universitárias no âmbito das ações culturais. InCID: Revista de Ciência da Informação e Documentação, Ribeirão Preto, v. 1, n. 2, p. 103-121, jul./dez. 2010. Disponível em: <http://www.revistas.usp.br/incid/article/view/42323>. Acesso em: 26 mar. 2015.

SANTOS, B. S. Um discurso sobre as ciências. 7. ed. São Paulo: Cortez, 2010.

SILVA, A. M. Mediações e mediadores em ciência da informação. Prisma.com, n. 9, 2010, p. 1-37. Disponível em: 〈http://revistas.ua.pt/index.php/prismacom/article/view/700>. Acesso em: 26 mar. 2015.

SILVA, J. L. C.; GOMES, H. F. A importância da mediação para a construção de uma autonomia no contexto dos usuários da informação. Informação e Sociedade: estudos, João Pessoa, v. 23, n. 2, p. 33-44, maio/ago. 2013. Disponível em:

<http://www.ies.ufpb.br/ojs/index.php/ies/article/view/12958>. Acesso em: 26 mar.2015.

SMIT, J. W. A informação na ciência da informação. InCID: Revista de Ciência da

Informação e Documentação, Ribeirão Preto, v. 3, n. 2, p. 84-101, jul./dez. 2012. Disponível em: 〈http://www.revistas.usp.br/incid/article/view/48655>. Acesso em: 26 mar. 2015.

Novas abordagens na organização, no acesso e na transferência da informação. In:

SILVA, H. C.; BARROS, M. H. T. C. (Org.). Ciência da informação: múltiplos diálogos. Marília: Oficina Universitária Unesp, 2009.

TÁLAMO, M. F. G. M.; SMIT, J. W. Ciência da informação: pensamento informacional e integração disciplinar. Brazilian Journal of Information Science, Marília, v. 1, n. 1, p. 3357, jan./jun. 2007.

TONELLO, I. M. S.; LUNARDELLI, R. A.; ALMEIDA JÚNIOR, O. F. Palavras-chave: possibilidades de mediação da informação. Ponto de acesso, Salvador, v. 6, n. 2, p. 21-34, ago. 2012. Disponível em:

<http://www.portalseer.ufba.br/index.php/revistaici/article/viewArticle/4524>. Acesso: 26 mar. 2015. 